Artigos

\title{
Reflexões Sociológicas Sobre Memória e Políica
}

Barbara Goulart ${ }^{1}$

Resumo: O presente artigo discorre sobre questões teóricas envolvendo o estudo sociológico de memórias. São feitas algumas considerações sobre o conceito de memória coletiva, argumentando que vai além de um conjunto de memórias individuais, pois é resultado de um processo coletivo de rememoração. Analiso, então, a questão das memórias políticas do Holocausto, abordando depois outros contextos de Justiça de Transição, e, finalmente, focando no caso brasileiro. O objetivo do texto é apontar para a possibilidade de ampliação do horizonte de pesquisa na temática, por meio da valorização da dimensão política do processo coletivo de rememoração.

Palavras-chave: Memória Coletiva; Memória Política; Rememoração; Justiça de Transição

\section{Sociological Reflections on Memory and Politics}

Abstract: This paper reflects on some theoretical issues involving the sociological study of memory. I present considerations on the concept of collective memory, arguing that collective memory is more than a set of individual memories, because it is in itself the result of a collective process of remembering. I then analyze the political memories of the Holocaust, later approaching other Transitional Justice contexts, and, finally, focusing on the Brazilian case. The objective is to point out

1 Programa de Pós-Graduação em Sociologia e Antropologia da Universidade Federal do Rio de Janeiro (PPGSA- UFRJ) - Rio de Janeiro - Brasil - barbara_4578@hotmail.com 
to the possibility of amplifying the analytical horizon on the subject, through valuing the political dimension of the collective process of remembering.

\section{Keywords: Collective Memory; Political Memory; Remembering; Transitional Justice}

\section{Introdução}

A questão da memória foi trabalhada pela primeira vez na sociologia - de maneira sistemática - por Maurice Halbwachs (1950/1990), considerado o grande clássico da literatura sobre o assunto. $\mathrm{O}$ autor trabalha com o conceito de memória coletiva, que seria aquela memória comum a todo um grupo social, que mantém lembranças sobre o seu próprio passado coletivo. A obra de Halbwachs foi influenciada majoritariamente pelas ideias de Émile Durkheim e Henri Bergson. De Bergson, Halbwachs herda a necessidade de problematização do tempo e da memória, valorizando a dimensão subjetiva da mente como fonte de conhecimento sobre o passado. De Durkheim, Halbwachs se apropria da questão da variabilidade das categorias perceptivas, formuladas não por sistemas aleatórios construídos pelas mentes individuais, mas com base em diferenças reais entre as diversas organizações sociais existentes (Olick; Vinitzki-Seroussi; Levy, 2011:10).

Buscando distanciar-se da perspectiva individualista estabelecida por Bergson, em Halbwachs o caráter propriamente social da memória é enfatizado. Para ele, as lembranças, pessoais ou impessoais, são produzidas pelas relações sociais com os diversos meios coletivos. Inspirando-se na obra durkheimiana - que enfatiza a lógica grupal dos ritos e da religiosidade - Halbwachs defende que a memória seria resultante não de um hábito individual, mas de uma prática social do grupo, ou da coletividade (Alberto, 2013).

Portanto, é possível dizer que para Halbwachs, a memória não existe na realidade espiritual individual, além da matéria, mas sim por meio da interação de indivíduos na realidade concreta ${ }^{2}$. Assim, para Halbwachs (1990), a memória seria socialmente construída. Por isso, seu trabalho adquire caráter sociológico, em vez de filosófico, como era a obra de Bergson. Adotando também a perspectiva organicista de Durkheim, Halbwachs (1990) enfatiza os aspectos harmônicos da construção das memórias coletivas, que serviriam para dar coesão social

2 Bergson (1896/2010) acreditava na existência de uma lembrança pura, inalterada, que faria parte da realidade do espírito, existindo além da matéria. Entretanto, essa memória “verdadeira" seria inatingível ao homem consciente. A consciência individual seria capaz então de escolher quais elementos serão trazidos à superfície, porém, esse processo seria sempre parcial e fragmentado, nunca em sua totalidade. É na obra Les Cadres Sociaux de la Mémoire, publicada originalmente em 1925, que Halbwachs critica essa perspectiva espiritualista presente na obra de Bergson. 
às coletividades, formando a chamada "comunidade afetiva". Nesse caso, a memória nacional seria a forma mais completa de memória coletiva.

Foi apenas com a obra de Pollak (1989) que os aspectos coercitivos da memória coletiva foram sublinhados, analisando-a como uma forma específica de violência simbólica praticada pelos setores dominantes da sociedade, que definem de forma impositiva a versão da História que comporá a memória da nação. Assim, Pollak questiona o processo de negociação da memória coletiva proposto anteriormente por Halbwachs (1990). Seguindo linha similar, Portelli (1996) sublinha os aspectos ideológicos da memória coletiva, que deve ser analisada criticamente. Para ele, haveria memórias divididas, nas quais grupos sociais distintos apresentariam versões diferentes para os mesmos acontecimentos históricos. Assim, discursos sobre eventos traumáticos do passado são marcados não apenas por dor e luto, mas também por ideologias.

É exatamente porque as experiências são incontáveis, mas devem ser contadas, que os narradores são apoiados pelas estruturas mediadoras da linguagem, da narrativa, do ambiente social, da religião e da política. As narrativas resultantes - não a dor que elas descrevem, mas as palavras e ideologias pelas quais são representadas - não só podem, como devem ser entendidas criticamente (Portelli, 1996: 108).

Com base no debate proposto por Halbwachs (1990), Pollak (1989) e Portelli (1996), é possível refletir sobre algumas questões teóricas presentes nos estudos sobre memória no âmbito da sociologia. Grande parte da literatura brasileira sobre memória tem como foco principal a questão do patrimônio, da oralidade, ou da própria História Oral como método de pesquisa. Entretanto, argumento que por meio de outros estudos, é possível ampliar o horizonte de pesquisa, valorizando principalmente a dimensão política do processo coletivo de rememoração. O objetivo do artigo é mostrar que alguns conceitos podem ser entendidos em maior profundidade para que se compreenda melhor os diversos objetos de estudo possíveis dentro do campo da memória. Para isso, primeiramente faço algumas considerações teóricas sobre a ideia de memória coletiva. Depois analiso a questão das memórias políticas do Holocausto, abordando em seguida outros contextos de Justiça de Transição, e, finalmente, focando no caso brasileiro.

\section{Memória Coletiva}

Em Halbwachs (1990), é possível perceber que o próprio conceito de memória coletiva, proposto por ele, enfatiza os aspectos coletivizantes da memória, 
criando uma ilusão de unidade de perspectivas. Como solução para o impasse, Fentress e Wickham (2003) propõem a adoção do conceito de memória social, em vez de memória coletiva, pois o último estaria desconectado dos processos de pensamento reais de qualquer pessoa concreta e poria excessiva ênfase nos aspectos coletivos da consciência social (Fentress; Wickham, 2003: 13).

Segundo eles, o conceito de memória social, além de fazer justiça plena ao lado coletivo da vida consciente individual, também evitaria uma conversão do indivíduo em uma espécie de autômato que obedece passivamente à vontade coletiva interiorizada (Fentress; Wickham, 2003: 13). Dessa maneira, Fentress e Wickham buscam se afastar de Durkheim, cuja presença ainda é muito forte na obra de Halbwachs, influenciado pelo determinismo do coletivo (Peralta, 2007: 6). Portanto, a ênfase dos autores recai sob os aspectos socializantes - em vez de coletivizantes - da memória, em que apesar de ser compartilhada entre muitos, a rememoração é vista como um processo individual de lembrar do passado, realizado por "pessoas concretas". Porém, é preciso pontuar que muitas vezes essas memórias coletivas podem ir além de "pessoas concretas". Algumas análises privilegiam o estudo de rememorações coletivas de eventos históricos passados, como por exemplo, eventos que celebram vítimas de guerra. Nesse caso, a análise recai sob as evidências externas de rememoração, como símbolos comemorativos, rituais e tecnologias.

Divergindo de Fentress e Wickham (2003), Kansteiner (2002) argumenta que a característica definidora da memória coletiva é justamente o fato de fazer parte da memória mesmo daqueles que não participaram do evento. Assim, as memórias coletivas podem ir além dos "processos de pensamento reais de qualquer pessoa concreta" (Fentress; Wickham, 2003: 13), pois vão além das experiências pessoais individuais. Para isso ser possível, a memória coletiva precisa contribuir para os interesses contemporâneos, sendo capaz de transcender à época em que o evento ocorreu. Apesar de não ter mais a alta carga emotiva que tinha para aqueles que sofreram com o evento em questão, a memória ganha vida própria quando se torna coletiva, pois molda as identidades de grupo e as visões de mundo dos indivíduos (Kansteiner, 2002: 188).

Pierre Nora (1993) apresenta argumento similar, declarando que a onda de recordação - característica do Século XX - resulta na construção de lugares de memória, ou "lieux de mémoire". Esses lugares podem existir de maneira concreta, como um museu, por exemplo, ou de maneira simbólica e abstrata, como uma celebração nacional. Os lugares de memória - abstratos ou concretos - são fruto da memória coletiva, pois possuem uma memória própria e existem para além das narrativas individuais sobre o passado. 
Em outro texto, Nora (2009) reafirma o caráter coletivo desses "traços do passado", pois vão além do processo individual de rememoração, tornando-se memórias quase-formais e objetivas. Em vez dos indivíduos terem suas memórias, hoje são os coletivos que as têm. São essas memórias objetivas, ou coletivas, que ligam "a lealdade do indivíduo ou da coletividade firmemente ao passado - real ou imaginário - e à sensação de pertencimento, consciência coletiva e autoconsciência" (Nora, 2009: 6). Assim, o conceito de memória está ligado à ideia de identidade. $\mathrm{O}$ autor explica que a "absoluta incerteza que pesa hoje sobre o futuro" cria para o presente a "obrigação de recordar". Isso exige uma acumulação assídua de artefatos, traços visíveis e sinais materiais que constituem evidência da existência de certo grupo identitário, seja uma família, nação ou religião. De maneira melancólica, Nora acredita que isso acaba nos afastando do passado, pois não nos relacionamos mais com ele de maneira espontânea, mas apenas sob a forma de traços. Só conseguimos recuperá-lo por meio de uma reconstrução, seja documental arquivística, seja monumental (Nora, 2009: 7).

\section{Discussões sobre o Holocausto}

Nora acrescenta que com o fim dos regimes totalitários do Século XX, diversas minorias conseguiram promover o reconhecimento de sua singularidade por meio da afirmação de suas memórias. "A força explosiva gerada pelas memórias dessas minorias tem tido o efeito de modificar consideravelmente o respectivo status e também a relação recíproca entre História e recordação" (Nora, 2009: 8). Um dos maiores exemplos históricos desse processo é o caso dos judeus e do Holocausto. Com base nas lembranças da Shoah, os judeus conseguiram utilizar a memória como forma de protesto contra o anti-semitismo e pela reivindicação de um Estado próprio, o que foi concretizado com a criação de Israel.

Vale a pena se estender aqui nas memórias sobre o Holocausto, pois ele foi objeto de estudo de muitos trabalhos sobre memória (Pollak, 1989; Alexander, 2002; Bauman, 1998; entre outros), muito provavelmente por causa de seu caráter traumático. Pollak (1989) enfatiza que muitas das vítimas do nazismo escolheram permanecer invisíveis, preferindo se silenciar sobre o seu passado. Entretanto, é impossível negar que o Holocausto se tornou um trauma coletivo, difícil de ser esquecido. Apesar das memórias individuais das vítimas permanecerem "subterrâneas", pois configuram o "não dito" (Pollak, 1989). Jeffrey Alexander (2002) argumenta que é explícito e visível o processo de inculcação de uma memória já construída sobre o Holocausto naqueles que nem mesmo vivenciaram os eventos em questão. 
Apesar das memórias de vítimas individuais do Holocausto - principalmente dos sobreviventes - serem talvez desconhecidas, ou subterrâneas, como disse Pollak (1989), Jeffrey Olick (2005) aponta que há uma memória coletiva sobre o nazismo já consolidada e que essa memória de forte condenação do nazismo não é subterrânea. $\mathrm{O}$ autor argumenta que a culpa coletiva dos alemães é bastante forte, resultando em um complexo processo político de negociação do difícil legado nazista. Portanto, talvez não seja apenas uma questão de silenciamento, como havia sugerido Pollak (1989), mas de acomodação de memórias. De fato, Olick (2005) afirma que na sociedade alemã do pós-guerra - anos 1950 - não houve um esquecimento do passado nazista na Alemanha, pois os líderes políticos estavam preocupados com a existência de resíduos do nacional socialismo no país (Olick, 2005: 5).

A diferença de resultados nas pesquisas de Pollak (1989) e Olick (2005) mostra com clareza a diferença entre duas fontes de pesquisa para o estudo das memórias. Enquanto o primeiro autor busca analisar as memórias de vítimas específicas do Holocausto, o segundo busca analisar a memória nacional alemã sobre o nazismo. Nesse caso, a memória das vítimas do Holocausto é marcada pelo silenciamento, pois elas têm dificuldade de falar sobre seu sofrimento, pois provoca culpa ou ambivalência entre seus interlocutores (Pollak, 1989: 6). Enquanto isso, a memória sobre o nazismo já era pública, mesmo que a questão do Holocausto ainda não aparecesse como elemento central nos anos 1950 (Olick, 2005).

Olick (2005) pontua que de fato passou-se muito tempo entre a liberação dos campos de concentração e a exposição dos horrores do Holocausto para o mundo. Segundo o autor, até mesmo em Nuremberg, o objetivo principal não era punir os culpados pelo Holocausto, mas sim punir os principais líderes nazistas pelos crimes de guerra, de maneira geral. Inicialmente, o extermínio dos judeus era visto como uma consequência da guerra - um evento espasmódico - e não como um fim em si mesmo do regime nazista (Olick, 2005: 106). Assim, no primeiro momento, a questão judaica estaria mesmo em segundo plano. Porém, isso não significa que não havia na Europa memórias sobre o passado nazista.

Analisando a memória pública alemã - com base em discursos e reportagens de jornal - Olick (2005) demonstra que houve um intenso debate entre os políticos alemães sobre os efeitos a longo prazo do passado nazista. De fato, sua perspectiva pode ser considerada polêmica. Em suas palavras, o autor argumenta o seguinte: 
"It turns out that, technically speaking, there was in fact no "silence" about the Nazi past in the 1950s, during which time West Germany's political leaders were significantly preoccupied with the residues of National Socialism and, in particular, with the purgative measures imposed by the occupation authorities in the immediate aftermath of the war (Olick, 2005:5)"3.

É esse debate sobre o passado nazista na Alemanha que Olick analisa na sua obra In the House of the Hangman: The agonies of the German defeat (1943-1949) (2005). Entretanto, o livro mostra que esse debate não aparece nas memórias individuais, ele aparece nos jornais e discursos políticos da época. Assim, a pesquisa não é baseada nos relatos individuais das vítimas do Holocausto - como o trabalho de Pollak (1989) - mas no mundo material, nos jornais e discursos políticos realizados em público sobre o regime nazista. Assim, enquanto as vítimas do Holocausto rememoravam em grande parte de maneira privada, o governo alemão do pós-guerra tratava de realizar eventos coletivos para expurgar o seu passado violento. Ao mesmo tempo, os políticos buscavam encontrar uma maneira de conciliar a nova democracia com o passado indigesto do nazismo.

Para complexificar a questão, é possível pensar também na importância de uma memória coletiva sobre o Holocausto para a sociedade contemporânea. Como foi visto até agora, Olick (2005) argumenta que, na época em que ocorreu, o Tribunal de Nuremberg estava mais associado à punição dos crimes de guerra do que ao Holocausto (Olick, 2005: 108). Porém, é inegável que nas memórias construídas posteriormente e no imaginário político sobre o evento, ocorre exatamente o oposto. Nuremberg é hoje lembrado como o tribunal que condenou os responsáveis pelo massacre dos judeus.

Jeffrey Alexander (2002) analisa esse assunto e argumenta que a memória coletiva sobre o Holocausto serve como elemento trágico que permitiu um raro aprendizado moral coletivo, principalmente na Europa e nos Estados Unidos, onde o trauma foi mais agudo. De fato, o texto de 2002 não discute questões mais contemporâneas, como a volta do fascismo e o neonazismo. Porém, Alexander é capaz de mostrar como o genocídio dos judeus permitiu posteriormente a formalização de uma justiça étnica, racial e religiosa, de reconhecimento mútuo, para que futuros conflitos globais fossem regulados de forma mais civilizada 4 . 
Assim, foi depois do Tribunal de Nuremberg, criado para condenar nazistas, que se formalizou um processo de Justiça de Transição. Aliás, foi por causa do Holocausto que o termo genocídio surgiu, sendo definido como a tentativa de destruir um povo em sua totalidade. Apesar do termo ter sido criado durante o período da guerra, ele foi utilizado de forma ampla apenas depois da descoberta das atrocidades cometidas pelo nazismo (Alexander, 2002: 19).

Alexander (2002) continua explicando como a sociedade americana passou a associar a luta contra o antissemitismo à luta pela democracia, mas o que importa aqui é enfatizar a importância das memórias de um evento passado para a solução de dilemas contemporâneos. Foi apenas quando o nazismo passou a ser visto coletivamente como o 'mal encarnado' - por meio de um processo mnemônico a posteriori, que se intensificou com a descoberta dos horrores do Holocausto - que foi possível desenvolver um caminho de aprendizado moral entre a população, buscando impedir atos similares no futuro, pois passou-se a considerar responsabilidade de todos o impedimento do sofrimento coletivo.

Levando em consideração a leitura de Adorno (1995), Jeanne Marie Gagnebin (2006) argumenta que esse processo ainda não terminou e que o silêncio permanece. Segundo ela "devemos lembrar do passado, sim; mas não lembrar por lembrar, numa espécie de culto ao passado" (Gagnebin, 2006: 103). O mais importante nesse processo seria o Aufklärung, palavra alemã utilizada no texto de Adorno (1995) e que significa Esclarecimento. Assim, seu argumento é que para não se esquecer do passado não basta produzir comemorações solenes em honra às vítimas do Holocausto, mas é preciso ir além, fazendo uma análise profunda do passado que produza instrumentos para melhor esclarecer o presente. Isso não seria suficiente para lutar contra o racismo e o fascismo, porém, mesmo assim, seria indispensável.

Explicando melhor, ela argumenta que é preciso ir além de definir juízes e acusados, encontrando culpados pelo Holocausto. A exigência é justamente separar a questão da culpabilidade da questão da elaboração do passado. Ela defende um lembrar ativo:

(...) um trabalho de elaboração e de luto em relação ao passado, realizado por meio de um esforço de compreensão e de esclarecimento — do passado e, também, do presente. Um trabalho que, certamente, lembra dos mortos, 
por piedade e fidelidade, mas também por amor e atenção aos vivos (Gagnebin, 2006: 105).

Com base nisso, é possível utilizar o trabalho do filósofo Henri Lefebvre (1983) para mostrar a complexidade do campo da memória e as disputas em torno do tema. Nesse caso, as memórias não devem ser tratadas apenas como lembranças ou recordações, mas como representações do passado5. Sobre isso, Lefebvre explica:

(...) representações não são simples fatos, nem resultados compreensíveis por sua causa e nem simples efeitos. São fatos de palavras (ou se preferir de discurso) e de prática social. Portanto, as representações e suas tendências provêm de 'sujeitos' sem se reduzir a uma subjetividade, e tem uma objetividade sem se reduzir a objetos sensíveis ou sociais, muito menos a 'coisas' (Lefebvre, 1983: 94-95).

Nesse sentido, as memórias sobre o Holocausto e sobre o nazismo não são 'coisas' a serem compreendidas na sua totalidade. Ao mesmo tempo, elas são construídas por sujeitos, mas vão além deles, pois existem para além das vítimas individuais. Assim, não são apenas subjetivas, pois constituem de fato uma memória, ou melhor, várias memórias coletivas sobre o passado.

Como acrescenta Lefebvre (1983), essas representações interferem na realidade, produzindo movimentos e acendendo disputas sobre o passado. Lefebvre então recupera um argumento já clássico nos estudos sobre memória - presentes, por exemplo, em Bergson (2010) e Benjamin (1987) -, afirmando que as representações não são verdadeiras por vocação, por essência. E tampouco são falsas. São operações interiores, atividades reflexivas, que conferem veracidade ou falsidade, dependendo de como se relacionam com as condições de existência de quem as produzem (Lefebvre, 1983: 52). Assim, elas não devem ser distinguidas entre falsas e verdadeiras, mas entre estáveis e móveis, entre reativas e superáveis, em alegorias e estereótipos incorporados de maneira sólida nos espaços e instituições (Lefebvre, 1983: 24).

5 Vale a pena se aprofundar aqui na discussão de Lefebvre sobre os conceitos de representação e memória. Para ele, representação vai além de memória, afirmando que a representação faz parte da vida humana, servindo como formas de reelaborar e comunicar o mundo. Entretanto, elas são ainda aproximações da realidade, que não podem substituir o mundo vivido. Nesse sentido, aquilo que se representa está presente na representação, mas ausente ao mesmo tempo, pois a representação nunca é igual ao representado, pois o vivido nunca é igual ao concebido. Levando essa discussão para o campo da memória, é possível afirmar que a memória do vivido - uma forma de representação - nunca é igual ao que de fato foi vivido. 
Seguindo o conceito de Lefebvre, argumento que as "representações" do Holocausto ainda interferem na realidade e provocam disputas. Por isso, acredito que quando escrevemos sobre a memória coletiva desse acontecimento - ou de qualquer outro evento político de magnitude -, é interessante pensar não apenas nas memórias das vítimas em questão - que sofreram com os eventos -, mas analisar também as memórias da própria sociedade - dos espectadores -, que também são múltiplas e diferenciadas, e que são construídas para que o país possa lidar com o seu passado violento e criminoso. Nesse caso, até mesmo aqueles que nasceram muito tempo depois dos fatos relatados, precisam se posicionar em relação ao passado comum.

Argumento que por causa da força das memórias do Holocausto, judeus que nasceram muitas décadas depois da segunda guerra mundial, se sentem pessoalmente afetados e indignados com o nazismo, pois se tornou uma memória coletiva. Até mesmo católicos fervorosos, ateus, protestantes e membros de qualquer outra religião se sentem pessoalmente indignados com o Holocausto, pois faz parte de uma memória coletiva supranacional e supra-religiosa, que condena os atos cometidos pelo nazismo. Como escreveu Olick (1999), o trauma de Auschwitz não vai desaparecer com a morte do último sobrevivente. $\mathrm{E}$ o trauma não é carregado apenas pelos descendentes das vítimas. Auschwitz é um trauma para a própria modernidade e sua moralidade (Bauman, 1998). Assim, faz sentido, eticamente e conceitualmente, afirmar que o trauma não pode ser reduzido a uma psicologia individual ou agregada (Olick, 1999: 345).

\section{Debates sobre Justiça de Transição}

Por meio do que foi dito sobre o Holocausto, é possível tratar aqui dos processos de Justiça de Transição ocorridos após o caso alemão. Trabalhando com as memórias surgidas diante da vivência de grupos oprimidos ou de vítimas de crimes políticos, Pollak (1989) comenta sobre as memórias subterrâneas, silenciadas e não-ditas. Ele argumenta que essas memórias:

"[testemunham] a vivacidade das lembranças individuais e de grupos durante dezenas de anos, e até mesmo séculos. Elas se opõem a memória nacional, considerada legítima, e são transmitidas no quadro familiar, em associações, em redes de sociabilidade afetiva e/ou política. Essas lembranças proibidas (caso dos crimes estalinistas), indizíveis (caso dos deportados) ou vergonhosas (caso dos recrutados à força) são zelosamente guardadas em estruturas de comunicação informais e passam despercebidas pela sociedade englobante (Pollak, 1989: 8). 
Diante disso, argumento que essas memórias são não-ditas porque a memória a qual elas se opõem, a memória nacional, é considerada coercitiva. Assim, Pollak coloca em outro momento que as memórias subterrâneas evidenciam o "caráter destruidor, uniformizador e opressor da memória coletiva nacional".

Se apropriando de Wood $(1999)^{6}$, é possível falar também em memória pública, dizendo que esse tipo de rememoração atesta para a vontade ou desejo de um grupo social, ou dispositivo de poder, de selecionar e organizar representações do passado para que essas representações sejam abraçadas pelos indivíduos como se tivessem emanado deles próprios (Wood, 1999: 2). Assim, é um processo intencional de criação de memórias nacionais, realizado pelos setores dominantes. É preciso enfatizar que por setores dominantes digo aqueles que ocupam postos de poder. Por exemplo, até mesmo na Revolução Russa, que tinha como lema a ascensão do proletariado - a classe dominada - a classe política soviética dominante, que tomou o poder durante o stalinismo, buscou esconder a memória de perseguição aos seus opositores, como também mostrou Pollak (1989).

Entretanto, a questão da coerção precisa ser aqui pontuada, pois mesmo afirmando que pode haver uma memória coercitiva, a questão da adesão está sempre presente. Apesar de ser formada por meio da dominação, essa violência precisa ser legitimada ao longo do tempo, permitindo que o autoritarismo se instale diante de uma socialização violenta. Isso ocorre em todos os governos autoritários. Utilizando o exemplo anterior, foi preciso que a sociedade alemã apoiasse o nazismo e a perseguição aos judeus - mesmo que a extensão da violência nos campos de extermínio ainda não fosse de conhecimento público para que ele fosse instalado e permanecesse no poder.

Ao mesmo tempo, são nos momentos em que afloram as memórias subterrâneas que a memória entra em disputa (Pollak, 1989: 4). É apenas quando surgem outras memórias que o caráter coercitivo dessas memórias políticas prévias fica evidente. Como disse Pollak (1989), inicialmente essas memórias são subterrâneas e não-ditas, existindo apenas no espaço privado. Porém, elas afloram em momentos de crise e ela "entra em disputa" (Pollak, 1989: 4). Essas novas memórias vão contra o que é imposto pelos setores dominantes da sociedade e pela memória oficial do Estado.

Por isso, as memórias subterrâneas também podem se tornar memórias dominantes se houver um movimento intenso para divulgá-las - o que de fato Nancy Wood (1999) escreve sobre o conceito de memória pública, que ela diferencia da memória indivi-
dual, produto do inconsciente. 
ocorreu nos dois exemplos analisados por Pollak (1989): a memória dos crimes do stalinismo e a memória dos crimes do nazismo. Comentando sobre o primeiro caso - as memórias dos crimes stalinistas -, Pollak argumenta que houve uma irrupção de ressentimentos acumulados no tempo e de uma memória da dominação e de sofrimentos que jamais puderam se exprimir publicamente. Foi um sopro de liberdade de críticas, despertando traumatismos profundamente ancorados que ganham forma em um movimento popular que se organiza em torno do projeto de construção de um monumento à memória das vítimas de Stalin (Pollak, 1989: 5).

Entretanto, Pollak não diz o mesmo sobre o nazismo. Nesse caso, ele argumenta que os sobreviventes dos campos de concentração precisaram encontrar um modo de conviver com aqueles que consentiram ou pelo menos assistiram a sua deportação. A dificuldade de se lidar com esse passado teria levado a um silenciamento dessas memórias. De fato, isso é verdade a nível individual. Contudo, a existência do Tribunal de Nuremberg e trabalhos como os de Alexander (2002) demonstram que após a descoberta do Holocausto, houve movimentos políticos importantes de condenação ao nazismo. Ao longo das décadas, o Holocausto se tornou um trauma coletivo, levando inclusive à formação de Israel.

Mas de fato, permaneceu o silêncio em torno daqueles que não participaram ativamente dos crimes nazistas, mas que foram coniventes com a perseguição dos judeus, como foi o caso de grande parte de população alemã. Isso nos leva a uma discussão mais complexa sobre Justiça de Transição, na qual é preciso discutir quem deve ser punido por crimes cometidos a nível nacional. Apenas os perpetradores ou todos os que foram coniventes? E como definir o que foi conivência? Os milhões de alemães que assistiram à deportação dos judeus foram coniventes? Por isso devem ser punidos? Ruti Teitel (2000) e José Zamora (2013) apresentam bons argumentos para mostrar que em todos os casos que envolvem a mudança de regimes ditatoriais em direção a regimes democráticos é necessário "virar a página". Para isso, é necessário punir os principais perpetradores, mas não é possível punir uma população inteira.

Analisando o caso de Justiça de Transição na África do Sul pós-Apartheid, a socióloga Claire Moon (2006) explica que o processo de reconciliação é uma ficção transformativa, que confere unidade moral aos eventos ocorridos (Moon, 2006: 272). Os testemunhos das vítimas são necessários para saber o que ocorreu, assim como a punição dos principais perpetradores. Entretanto, o objetivo principal não é a punição de todos os que foram coniventes. O objetivo é "purgar ou purificar a nação dos pecados de seu passado violento, para que possa futuramente se reconciliar" (Moon, 2008: 92). Assim, o objetivo principal de 
tornar pública a memória das vítimas é a reconciliação da nação e não necessariamente a punição de todos os culpados - a condenação dos perpetradores seria apenas um subproduto da Justiça de Transição.

Com uma posição mais crítica, Vinyes (2015) argumenta que o que ocorre é uma privatização da memória, em que se tornaria impossível formar uma memória verdadeiramente pública sobre o passado, já que o próprio Estado preenche esse vazio com uma memória administrativa derivada da ideologia da reconciliação. Para ele, a ideologia da reconciliação não se assenta na realidade. Ao contrário, ela pretende criar a realidade, ou no máximo evitá-la. Assim, os elementos antagônicos das memórias sobre as ditaduras - sobre o nazismo, por exemplo - são devorados, expandindo as certezas absolutas. A rememoração se torna então um instrumento de assimilação, que comemora uma memória tranquilizadora de êxito adquirido após o sofrimento e vontade (Vinyes, 2015: 227).

É importante sublinhar aqui que mesmo não sendo possível punir todos os culpados e mesmo que de fato possa haver uma ideologia da reconciliação, o processo de Justiça de Transição permite a erupção de memórias por muito tempo guardadas pelas vítimas. Há então uma disputa política pela memória, na qual essas memórias das vítimas surgem em contraposição à memória oficial do Estado. Em todos os casos mencionados no presente artigo - stalinismo, nazismo, Apartheid, e também nas ditaduras latino-americanas que serão mencionadas nas próximas páginas - a memória oficial é aquela na qual não houve crimes cometidos pelo Estado, e a memória que está disputando a legitimidade é aquela em que se afirma que houve sim crimes cometidos pelo Estado. Assim, haveria um processo intencional de surgimento de memórias subterrâneas no campo político, no qual essas memórias buscam tornar-se legítimas, deslegitimando as memórias anteriores, que negavam ou escondiam os crimes cometidos pela ditadura.

É preciso mostrar também o papel fundamental do Estado no processo de construção e manutenção de memórias políticas. Como analisou Pierre Nora (1993), no pós-guerra houve uma desarticulação dos modos de vida tradicionais e da transmissão de cultura pela via oral e espontânea. Isso fez com que o Estado ocupasse esse lugar vazio, instaurando arquivos, museus e celebrações nacionais - os lugares de memória - como estratégia de legitimação dos Estados nacionais. Nesse processo, a memória se torna voluntária e deliberada. Analisando a disputa pela memória do período ditatorial na América Latina, Lifschitz (2015) argumenta que durante as ditaduras latino-americanas, essa nova articulação entre Estado e memória também se tornou dominante, na qual as 
memórias nacionais serviam para legitimar o Estado autoritário e negar os crimes cometidos por ele próprio.

Entretanto, como escreve o autor, "o universo da memória política não se encerra nesses parâmetros. Em certas conjunturas, como em algumas transições democráticas, irromperam memórias que confrontavam a memória oficial". Surge assim um "novo campo de forças" (Lifschitz, 2015: 20). Essas são as chamadas "memórias subterrâneas", de Pollak (1989). É necessário o apoio do Estado para que elas possam surgir, pois é ele o agente regulador do campo da memória política. Com a redemocratização dos países da América Latina e a por meio da pressão de movimentos sociais - como as Madres e Abuelas de la Plaza de Mayo, no caso argentino, o mais emblemático ${ }^{7}$-, o Estado é pressionado a mudar de posição, permitindo o ressurgimento das memórias silenciadas.

Argumento que esse processo aparece de maneira similar em todos os casos de Justiça de Transição, em que há mudança de um governo autoritário para uma democracia. É possível associar esse processo à filosofia da História de Walter Benjamin (1940/1987). De maneira normativa, Benjamin afirma que é necessário escrever a História por meio dos vencidos e não dos vencedores. Como explica Lowy (2002), "a exigência fundamental de Benjamin é escrever a história a contrapelo, ou seja, do ponto de vista dos vencidos - contra a tradição conformista do historicismo alemão cujos partidários entram sempre em empatia com o vencedor" (Lowy, 2002: 203).

Dialogando com a análise anterior, argumento que as memórias dos vencidos são as memórias subterrâneas, sufocadas pelo Estado e pelas classes dominantes. Benjamin (1987) escreve na sexta tese: "O dom de despertar no passado as centelhas da esperança é privilégio exclusivo do historiador convencido de que também os mortos não estarão em segurança se o inimigo vencer. E esse inimigo não tem cessado de vencer" (Benjamin, 1987). Argumento que esse incessante vencer do inimigo é a própria memória política dominante, pois ela retém o passado do vencedor no presente, o revivendo por meio de comemorações nacionais, eventos públicos etc., enfim, pelos lugares de memória descritos por Nora (1993). Portanto, haveria uma "tradição dos oprimidos", como argumenta Benjamin (1987) na oitava tese do ensaio Sobre o Conceito de História.

7 A associação civil Abuelas de Plaza de Mayo é uma organização de direitos humanos que tem como finalidade a localização dos bebês sequestrados pela ditadura militar argentina (1976-1983) e sua consequente reintegração às famílias de origem. As Madres de Plaza de Mayo formam uma outra associação argentina, que tem como fim a recuperação dos desaparecidos políticos da ditadura militar e o julgamento dos responsáveis pelos crimes de lesa humanidade. As duas associações muitas vezes atuam de forma conjunta, já que os bebês sequestrados são na maioria das vezes filhos de desaparecidos políticos. 
A expressão utilizada pelo autor - "tradição dos oprimidos" - sinaliza para a luta de classes, tema constante entre os intelectuais marxistas. Lowy (2005) afirma em seu estudo sobre a obra benjaminiana, que a expressão representa a história do passado, que é utilizada como instrumento nas mãos das classes dominantes. Assim, além dos dominados serem oprimidos no presente, eles seriam também oprimidos pela história, e é possível facilmente levar o argumento adiante e dizer que são oprimidos pela memória também, que é construída com base na experiência da classe dominante. Afirma Lowy, "extirpar a tradição ao conformismo que se quer dominar é restituir à história (...) sua dimensão de subversão da ordem estabelecida, edulcorada, obliterada ou negada pelos historiadores "oficiais"” (Lowy, 2005: 66). Somente assim será possível "despertar as centelhas do passado", como havia sugerido Benjamin. Assim, seria necessário escrever a história a contrapelo, que seria construída por meio da memória das classes dominadas, que podem ser consideradas também as vítimas das classes dominantes.

Diante disso, é possível argumentar que o autor defende a formação de uma História com base na memória das vítimas. Para ele, o sujeito do conhecimento histórico deve ser a própria classe combatente e oprimida ${ }^{8}$. Benjamin sugere que se volte a olhar para o passado, recuperando a memória dos vencidos, antes que se possa voltar a olhar novamente para o futuro. Como foi dito antes, é possível comparar esse processo ao que ocorreria posteriormente nos governos de Justiça de Transição $0^{9}$, no qual é necessário que o país passe por um momento de expurgo do passado traumático coletivo, para que seja possível olhar para o futuro novamente e "virar a página".

Em toda a obra de Benjamin é possível perceber uma revalorização do passado, que estaria sendo devastado pela modernidade. Em O Narrador, Benjamin defende a necessidade de valorizar a prática da narração, perdida com a volta dos soldados da guerra que permanecem em silêncio. No mundo moderno capitalista, marcado pelo individualismo e pela concorrência, a narração - voltada a contar o passado para o coletivo do presente - perde o seu espaço. Há então um desencantamento do mundo e um tom nostálgico em suas obras, característica partilhada com outros autores da Escola de Frankfurt, como Adorno (1995),

8 Como é característico do marxismo, é claro que Benjamin (1987) entende como vencidos a classe política do proletariado e como vencedores a chamada burguesia e anteriormente a aristocracia.

9 É preciso lembrar que Benjamin escreveu muito antes do Tribunal de Nuremberg, primeira experiência de Justiça de Transição, ser instalado. Entretanto, Benjamin parece ter antevisto o que viria acontecer na Europa após a sua morte, já que sua análise é muito apropriada para se estudar os processos de transição democrática. 
mencionado anteriormente. Como é expresso em $O$ Narrador, a tradição oral estaria em extinção.

São cada vez mais raras as pessoas que sabem narrar devidamente. É cada vez mais frequente que, quando o desejo de ouvir uma história é manifestado, o embaraço se generalize. É como se estivéssemos sendo privados de uma faculdade que nos parecia totalmente segura e inalienável: a faculdade de intercambiar experiências (Benjamin, 1987: 197-198).

Essa discussão sobre a necessidade de valorização do passado e da narração do passado torna-se fundamental para o debate sobre Justiça de Transição. Como argumenta Ruti G. Teitel (2000), na Justiça de Transição, revisitar o passado é entendido como a única maneira de mover-se para frente. É possível associar esse processo ao argumento benjaminiano, no qual é necessário "despertar as centelhas do passado" dos oprimidos. Ao mesmo tempo, a análise de Javier Lifschitz (2015) - que estuda as memórias sobre as ditaduras militares na América Latina - também mostra que o passado das vítimas volta à cena política com a implementação da Justiça de Transição em diversos países do continente.

Lifschitz defende a existência de um poder espectral dos mortos, ou das vítimas mortas da ditadura, que, assim como os oprimidos de Benjamin, também demandam um retorno ao passado. Inspirado na ideia do espectro do comunismo, enfatizado por Marx e Engels na primeira frase do seu Manifesto ${ }^{10}$, Lifschitz argumenta que os espectros políticos têm poder, pois apesar de não serem vistos ou ouvidos, eles projetam uma imagem e uma voz que reaparecem (Lifschitz, 2015: 36). No caso das ditaduras latino-americanas, por meio dos testemunhos dos sobreviventes, os mortos são lembrados. Assim, essas figuras do passado esquecido reaparecem no presente, por meio dos testemunhos daqueles que os conheceram e com quem lutaram.

\section{Caso Brasileiro}

O conceito de Justiça de Transição é aplicado aos processos políticos que envolvem a mudança de regimes ditatoriais ou autoritários em direção à regimes democráticos de governo; ou de situações de conflito armado ou de violência política em direção à paz (Zamora, 2013: 21). Nesse caso, é necessário que esses

10 O Manifesto Comunista de Marx e Engels começa com a seguinte frase: "Um espectro ronda a Europa o espectro do comunismo". 
governos passem por um momento de expurgo desse passado traumático coletivo, para que seja possível olhar para o futuro novamente; ou "virar a página".

Esse processo político articula três categorias básicas: verdade, justiça e reparação (Napolitano, 2015: 96). Primeiro é necessário recuperar a verdade sobre o que aconteceu, o que foi ocultado pelo regime autoritário. Para isso é necessário coletar e divulgar os relatos das vítimas. Depois é necessário trazer justiça a essas vítimas, punindo os responsáveis pelos crimes. E em terceiro lugar, reparar essas vítimas pelos danos sofridos nas mãos do Estado. Essa reparação pode ocorrer financeiramente, por meio de indenizações monetárias, ou por outros caminhos que permitam a reconstrução dos laços sociais desses indivíduos com a sociedade, como um pedido de desculpas oficial do governo, por exemplo. Na maioria das vezes, a reparação inclui os dois passos.

No caso brasileiro, o processo de Justiça de Transição ficou marcado pela Lei da Anistia, promulgada em 1979, na qual o que foi definido, como sabemos, foi a "anistia ampla, geral e irrestrita". Enquanto os militares argumentam que esse modelo favoreceu os chamados "subversivos" - que não seriam mais julgados pelos crimes cometidos pela luta armada -, outros setores da sociedade defendem que, na prática, os mais favorecidos acabaram sendo os torturadores e chefes militares dos porões da ditadura, que nunca foram processados pelos seus crimes contra a humanidade. A brasilianista Leigh Payne (2008) chama o modelo brasileiro de anistia de "blanket amnesty" perpetradores de serem processados. Assim, não haveria accountability, pois os agentes da ditadura não seriam responsabilizados pelos seus atos (Payne, 2008: 9).

Agora é necessário pensar nas consequências desse modelo de anistia para o cenário político brasileiro. Argumento que a incapacidade legal de processar militares e policiais, fez com que o Estado brasileiro concentrasse seus esforços nas outras duas dimensões da Justiça de Transição. Portanto, no Brasil a questão da verdade e da reparação aparece de maneira muito mais evidente do que $\mathrm{o}$ aspecto punitivo da justiça. O reconhecimento da culpabilidade do Estado e a destinação de espaços públicos para que as vítimas contassem suas histórias fizeram com que a questão da justiça criminal ficasse em segundo plano e a dimensão da memória ganhasse o papel de protagonista no cenário político, mesmo que seja uma memória parcial desses mesmos eventos.

11 Em outro texto, o termo "blanket amnesty" é traduzido em português como "anistia protetiva" ou "anistia obstinada" (Olsen, et. al, 2013). A primeira tradução ilumina o aspecto de proteção da anistia, que protege os responsáveis pelos crimes da ditadura, e a segunda tradução ilumina o aspecto de persistência desse tipo de acordo, que não é capaz de superar o modelo de anistia proposto pelos militares e no qual a impunidade permanece. 
Até hoje ninguém foi efetivamente punido pelas vias legais por crimes cometidos pela ditadura militar, entretanto, alguns passos foram dados no Brasil para trazer à luz os crimes cometidos pelos militares e pela polícia, por meio de relatos públicos - nos quais aqueles que sofreram esses crimes podem contar a sua história - e para reparar as vítimas, por meio de indenizações pagas pelo Estado. É por isso que argumento que a dimensão da memória é fundamental no processo brasileiro de Justiça de Transição. A possibilidade de relatar publicamente o que sofreram serviu de amparo para as vítimas brasileiras, que não conseguiram ver seus algozes condenados. Como os militares não podem ser legalmente punidos, a memória serve hoje como veículo para que não se esqueça dos crimes cometidos ${ }^{12}$. As vítimas escrevem assim, no sentido benjaminiano, uma História baseada nos vencidos

Argumento que as memórias coletivas sobre a ditadura devem ser repetidas e difundidas para que não sejam esquecidas. Enquanto a memória do indivíduo permanece ao longo de sua vida, podendo ser recobrada a qualquer momento, a memória coletiva é muito mais fluida e vulnerável. Ela precisa ser lembrada não apenas pelo indivíduo que a viveu, mas por toda a comunidade da qual ele faz parte. Os livros autobiográficos e os eventos públicos organizados em memória das vítimas servem para isso. No processo histórico-social aqui analisado, a memória de uma vítima da ditadura passa a ter valor não apenas para a própria vítima em questão, mas se torna parte de toda a memória coletiva do país sobre aquele período. Os sobreviventes tornam-se portadores da memória dos crimes da ditadura, ou "arquivistas da tragédia"13" (Candau, 2005: 61). Assim, eles são representantes do que foi vivido não apenas por eles, mas pelo próprio Brasil, por isso suas memórias passam a ser de interesse nacional.

Grande parte da documentação sobre esse período é ainda de caráter sigiloso ou foi destruída pelos militares, preocupados em esconder os crimes cometidos pelo regime. Pela falta de documentos oficiais disponíveis e pela recusa dos militares em falar sobre o assunto, o testemunho das vítimas se torna peça central no quebra-cabeça de reconstituição da ditadura. Isso ocorre pelo motivo prático de ser uma das poucas fontes disponíveis para se descobrir o que

12 Sublinho que quando falamos em memórias sobre a ditadura, infelizmente estamos nos referindo a um setor muito pequeno da sociedade brasileira, com escolaridade e renda considerável, que conhece os eventos políticos que ocorreram no país entre 1964 e 1985. Estudo recente mostra que grande parte da população brasileira não tem conhecimento do que ocorreu no país nessa época e não tem memórias sobre a ditadura (Cerqueira; Motta, 2015).

13 Expressão cunhada pelo antropólogo Joel Candau (2005) para comentar sobre as vítimas do nazismo que publicaram suas memórias do período. 
realmente aconteceu, mas também pelo motivo moral de dar voz àqueles que foram silenciados por tanto tempo. $\mathrm{O}$ resultado disso é uma crescente "revalorização da primeira pessoa como ponto de vista" (Sarlo, 2007: 18). Beatriz Sarlo (2007) chama esse processo moral de "guinada subjetiva".

Ademais, as vítimas sobreviventes representam também aqueles que não sobreviveram. Sarlo (2007) aponta para o paradoxo do testemunho ${ }^{14}$, pois quem sobrevive para testemunhar, assume a primeira pessoa dos que seriam os verdadeiros testemunhos, os mortos (Sarlo, 2007: 35). É possível se apropriar também de uma expressão cunhada por James E. Young (1993): a "síndrome do túmulo ausente ${ }^{15}$. Ele argumenta que a ausência de corpos das vítimas resulta em um espaço de luto fisicamente vazio, e a escrita sobre a tragédia sofrida serve como possibilidade de criação de um local comemorativo, já que não há túmulos onde seja possível lembrar os entes perdidos. Posteriormente, locais físicos também são construídos para a comemoração, como museus ou memoriais. Como foi dito anteriormente, existe um "poder espectral dos mortos", que reclamam pela memória do passado, para que não sejam esquecidos (Lifschitz, 2015: 37).

A análise pode ser aplicada à ditadura militar brasileira - assim como de outros países latino-americanos - já que muitas vítimas nunca foram encontradas e foi necessário criar documentos e relatos escritos para comprovar e lembrar o ocorrido, porque não havia provas físicas das mortes. O trabalho da Comissão Nacional da Verdade no Brasil é um exemplo disso. Outro exemplo é a prática recorrente em diversos países latino-americanos de se dizer os nomes dos mortos, seguido da palavra "Presente!", pois explicita a necessidade de manter vivos na memória os abusos sofridos por aqueles que não puderam relatar o sofrido. Assim, apesar de fisicamente ausentes - muitas vezes até mesmo seus corpos nunca foram encontrados - eles estão vivos na memória dos sobreviventes.

Portanto, lembrar se torna um ato social e político, e o testemunho dos sobreviventes se transforma em elemento fundamental da reconstrução do passado. Não é por acaso que a "mania da memória" surgiu concomitantemente com o desenvolvimento da História do tempo presente, pois ainda há sobreviventes para relatar o ocorrido. $\mathrm{O}$ resultado desse processo foi a utilização do testemunho como fonte histórica, resultando também na hibridização entre memória autobiográfica e memória histórica (Candau, 2005: 61), pois muitos sobreviventes da ditadura decidiram escrever seus próprios livros de memória.

14 Apesar de o livro tratar sobre os testemunhos das vítimas da ditadura, nesse caso Sarlo (2007) está falando sobre os testemunhos dos sobreviventes do Holocausto. Entretanto, acredito que seu argumento possa ser aplicado para o caso das ditaduras militares.

"The missing gravestone syndrome" no original, expressão utilizada para falar sobre o Holocausto. 
Nesse processo, a História Oral também ganha força e se afirma como método de pesquisa. Para Sarlo (2007), foi um movimento de "devolução da palavra, em que a conquista da palavra e de direito à palavra se expande, reduplicado por uma ideologia de "cura" identitária por meio da memória social ou pessoal" (Sarlo, 2007: 39).

É importante sublinhar o papel do Estado brasileiro nesse processo, que em governos anteriores estimulou, liderou e financiou diversas iniciativas públicas de recolhimento de memórias. Para além da Comissão Nacional da Verdade, já citada anteriormente, vale a pena mencionar aqui o grande acervo do projeto iniciado em 2008, Marcas da Memória: História Oral da Anistia no Brasil, realizado em parceria da Comissão de Anistia do Ministério da Justiça com a Universidade Federal de Pernambuco (UFPE), a Universidade Federal do Rio Grande do Sul (UFRGS) e a Universidade Federal do Rio de Janeiro (UFRJ). O projeto foi coordenado pelos historiadores Antonio T. Montenegro, Carla S. Rodeghero e Maria Paula Araújo, e resultou também em um livro homônimo, organizado pelos mesmos e publicado em 2012. A presença desse acervo já comprova a importância atribuída às memórias da ditadura, dada a vastidão do projeto, que inclui 101 entrevistas, e também a presença ativa do Estado na preservação dessas memórias, já que foi financiado pelo Ministério da Justiça. O projeto também incluiu audiências públicas com os relatos das vítimas, e chamadas para iniciativas da sociedade civil, incluindo pesquisas, exposições, peças de teatro etc.

É interessante mencionar a presença da palavra "anistia" no título do projeto e também no nome da comissão que o financiou, pois salienta não os aspectos violentos do passado ditatorial, mas enfatiza o aspecto apaziguador e conciliador do processo de anistia, já que as memórias serviriam para curar as feridas do passado e não para revanchismos ou confrontos. Para Maria Paula Araújo (2012), que participou do processo, a palavra anistia aparece como sinônimo de reparação - no sentido simbólico e não financeiro do termo -, pois a publicação desses relatos faria parte da reparação de danos por parte do Estado brasileiro às vítimas da ditadura (Araújo, 2012: 15). Entretanto, argumento que essa reparação vai além das próprias vítimas em questão, e engloba toda a sociedade brasileira, pois é possível dizer que o testemunho serve para "purgar ou purificar a nação dos pecados de seu passado violento, para que possa futuramente se reconciliar" (Moon, 2008: 92).

Menciono também o livro 68: A geração que queria mudar o mundo (2011), também realizado pela Comissão da Anistia, e organizado por Eliete Ferrer, do qual participaram 100 autores em 170 relatos. No prefácio escrito pela equipe 
da Comissão de Anistia, os autores enfatizam que no Brasil, anistia significa memória. E essas memórias servem como fundamentos da reparação às violações, mas também como uma reflexão necessária sobre a importância da não repetição dos atos arbitrários cometidos pela ditadura. Enfatizam também que essa reparação é coletiva, pois como dizem os próprios, "esquecer a barbárie equivaleria a nos desumanizar"16. Corrobora assim meu argumento anterior, de que o testemunho das vítimas se torna parte da memória política - e coletiva - do país sobre a ditadura, pois é moralmente necessário que todos se lembrem do ocorrido.

Aponto agora para outros projetos de memória realizados durante os governos Luiz Inácio Lula da Silva e principalmente Dilma Rousseff. No site da Comissão da Anistia, é possível encontrar centenas de relatos e livros publicados pela comissão, destacando assim a iniciativa do governo em resgatar as memórias sobre a ditadu$\mathrm{ra}^{17}$. Menciono também o espaço antes reservado no site do Ministério da Justiça para aqueles que desejavam requerer sua anistia política ${ }^{18}$ (hoje inexistente), e o projeto Memórias Reveladas ${ }^{19}$ do Arquivo Nacional e institucionalizado pela Casa Civil da Presidência, que coloca à disposição do público os arquivos da ditadura que faziam parte da Agência Brasileira de Inteligência (ABIN). Há também o portal de internet Memórias da Ditadura ${ }^{20}$, realizado pelo Instituto Vladimir Herzog e apoiado pela Secretaria de Direitos Humanos da Presidência da República, que tem o objetivo de divulgar a História do Brasil no período de 1964 a 1985.

Vemos então o aspecto redentor adquirido pela memória. Argumento que a memória aparece para vingar a História. Já que as vítimas sofreram o que sofreram, e isso não seria possível mudar, é necessário então lembrar-se do ocorrido para que ele nunca mais se repita. A memória se torna um dever após o fim das ditaduras. Com a instalação do regime democrático no Brasil, as feridas puderam enfim ser expostas. Os diversos e incontáveis testemunhos que surgiram, possibilitaram a condenação do terrorismo de Estado e a ideia do "nunca mais" entrou no nosso vocabulário (Sarlo, 2007: 20). Mesmo que juridicamente ninguém tenha sido condenado no Brasil - por causa da Lei da Anistia -, moralmente, socialmente, politicamente, e até mesmo historicamente, houve uma explícita tentativa por parte do Estado de condenar os

16 A frase está na página 9 do livro, no texto escrito pela Comissão de Anistia, mas sem especificar o nome dos autores.

17 Disponível em: <http://memorialanistia.org.br>. Acesso em: 08 abr. 2020.

18 Disponível em: <http://justica.gov.br/seus-direitos/anistia>. Acesso em: 08 abr. 2020.

19 Disponível em: <http://www.memoriasreveladas.gov.br>. Acesso em: 08 abr. 2020.

20 Disponível em: <http://memoriasdaditadura.org.br/>. Acesso em: 08 abr. 2020. 
torturadores e colaboradores da ditadura, principalmente durante o governo Dilma Rousseff, ela própria vítima de tortura pelos militares. Por fim, é inevitável citar as recentes mudanças na atuação do Estado brasileiro no campo da memória. Elegendo para presidente da República um homem que defende publicamente a ditadura e seus torturadores, o Estado brasileiro deixa de exercer 0 papel que antes cumpria, de denúncia do passado autoritário.

Pollak (1989) afirmou a necessidade de associar uma profunda mudança política a uma revisão autocrítica do passado. Colocando o Brasil nessa discussão, devemos lembrar a importância da democracia para a reconstrução desse período ainda pouco esclarecido na História do país. É inquestionável que, apesar da ditadura ter acabado há mais de duas décadas, ela continua presente na memória dos brasileiros. Como escreveu Hannah Arendt (1961), "a ação que possui sentido para os vivos (...) só é completa nas mentes que a herdam e a questionam" (Arendt, 1961: 31). Assim, por ser um momento de clivagem, de interrupção da democracia e de radicalização ideológica, a ditadura, e o combate a ela, muito possivelmente permanecerão na História do Brasil, pois representam não apenas um evento traumático do passado, mas simbolizam a necessidade de reafirmar o modelo político democrático.

\section{Considerações Finais}

Halbwachs (1990), analisando o papel da memória coletiva, chegou à seguinte conclusão:

(...) ao lado de uma história escrita, há uma história viva que se perpetua ou se renova através do tempo e onde é possível encontrar um grande número dessas correntes antigas que haviam desaparecido somente na aparência. (...) A lembrança é em larga medida uma reconstrução do passado com a ajuda de dados emprestados do presente, e, além disso, preparada por outras reconstruções feitas em épocas anteriores e de onde a imagem de outrora manifestou-se já bem alterada (Halbwachs, 1990: 67 e 71).

Assim sendo, a memória seria uma reconstrução do passado realizada pelo presente. Nesse caso, argumento que as memórias não são construídas de forma aleatória, ou autoevidente, por meio de uma construção verificável da História do país, mas sim são construções parciais a partir de narrativas específicas sobre eventos que já ocorreram.

Por isso, é importante se perguntar, com tantos acontecimentos no mundo, o que faz certo evento permanecer na memória nacional e outro ser simplesmente 
esquecido ou apenas lembrado por amigos e familiares? Para analisar esse fenômeno é necessário adotar uma perspectiva construtivista, pois como argumentou Pollak (1989), "não se trata mais de lidar com os fatos sociais como coisas, mas de analisar como os fatos sociais se tornam coisas; como e por quem eles são solidificados e dotados de duração e estabilidade" (Pollak, 1989: 4).

Portanto, é preciso considerar o elemento político da construção de memórias, analisando os aspectos contraditórios entre os diversos discursos sobre 0 passado, mostrando assim a maleabilidade e parcialidade das memórias coletivas construídas pelas diversas sociedades, sendo continuamente capazes de transformar o passado por meio das questões do presente. Logo, os aspectos mutáveis e cambiantes das memórias devem ser enfatizados. As lembranças e os esquecimentos mudam de acordo com a conjuntura e com as possibilidades e necessidades políticas de cada época. É necessário então que pesquisemos essas mudanças, entendendo também por que elas ocorrem.

Concluo esta reflexão afirmando que a área da memória - principalmente da memória política - ainda é um campo problemático pouco estudado pelas ciências sociais no Brasil. Assim, é necessário investir mais nessa linha de estudos. Acredito que o ato de lembrar é fundamentalmente um ato social, no qual os indivíduos empregam categorias sociais e normativas para definir quais são os elementos que comporão a sua memória (Olick; Robbins, 1998: 134). Como disse Olick et. al. (2011):

Studying (and theorizing) memory allows us to shift our focus from time to temporalities, and thus to understand what categories people, groups, and cultures employ to make sense of their lives, their social, cultural, and political attachments, and the concomitant ideals that are validated (Olick; Vinitzki-Seroussi; Levy, 2011: 37) ${ }^{21}$.

Portanto, entender como a sociedade lembra é uma forma de entender também a própria sociedade em questão.

\section{Referências:}

ADORNO, Theodor W. Educação e Emancipação. Rio de Janeiro, Paz e Terra, 1995. ALBERTO, Diego. Maurice Halbwachs y los marcos sociales de la memoria: Defensa y

21 Tradução minha: "Estudar (e teorizar) sobre a memória nos permite retirar nosso foco da análise do tempo e mudá-lo para a análise das temporalidades. Logo, nos torna capazes de entender quais são as categorias que as pessoas, grupos e culturas empregam para dar sentido a suas vidas, seus vínculos sociais, culturais e políticos, e os ideais concomitantes que elas validam". 
actualización del legado durkheimiano: de la memoria bergsoniana a la memoria colectiva. In: X Jornadas de Sociología. Facultad de Ciencias Sociales, Universidad de Buenos Aires, 2013.

ALEXANDER, Jeffrey C. On the Social Construction of Moral Universals: The Holocaust from War Crime to Trauma Drama. European Journal of Social Theory, v. 5, n. 1, 2002, pp. 5-85.

ARAÚJO, Maria Paula. Memória, Testemunho e Superação: história oral da anistia no Brasil. História Oral, v. 15, n. 2, 2012.

ARENDT, Hannah. Between Past and Future: Six Exercises in Political Thought. New York, 1961.

BAUMAN, Zygmunt. Modernidade e Holocausto. Rio de Janeiro, Zahar, 1998.

BENJAMIN, Walter. Obras Escolhidas. v. 1. São Paulo, Brasiliense, 1987.

BERGSON, Henri. Matéria e Memória: ensaio sobre a relação do corpo com o espírito. São Paulo, Martins Fontes, 2010.

CANDAU, Joël. Anthropologie de la mémoire. Paris, Armand Colin, 2005.

CERQUEIRA, Adriano; MOTTA, Rodrigo. Memória e Esquecimento: o regime militar segundo pesquisas de opinião. História e memória das ditaduras do século XX, Rio de Janeiro, v. 1, Editora da FGV, 2015.

FENTRESS, James; WICKHAM, Chris. La Memoria Social. Valencia, Universidad de Valencia, 2003.

GAGNEBIN, Jeanne Marie. Lembrar, Escrever, Esquecer. São Paulo, Editora 34, 2006.

HALBWACHS, Maurice. A Memória Coletiva [1950]. São Paulo, Vértice/Revista dos Tribunais, 1990.

KANSTEINER, Wolf. Finding meaning in memory: A methodological critique of collective memory studies. History and Theory, v. 41, n. 2, 2002, pp. 179-197.

LEFEBVRE, Henri. La Presencia y La Ausencia: contribución a la teoría de las representaciones. México, Fondo de Cultura Económica, 1983.

LIFSCHITZ, Javier. La Memória Política y sus Espectros. United States, Editorial Académica Española, 2015.

LOWY, Michael. A Filosofia da História de Walter Benjamin. Estudos Avançados, v. 16, n. 45, 2002, pp. 199-206.

MOON, Claire. Narrating political reconciliation: South Africa's truth and reconciliation commission. Lanham, Lexington Books, 2008.

. Narrating political reconciliation: Truth and reconciliation in South Africa. Social \& Legal Studies, v. 15, n. 2, 2006, pp. 257-275,

NAPOLITANO, Marcos. Os historiadores na batalha da memória: resistência e transição democrática no Brasil. In: QUADRAT, Samantha Viz; ROLLEMBERG, Denise. História e Memória das Ditaduras do Século XX, v. 1. Rio de Janeiro, Ed. FGV, 2015. 
NORA, Pierre. Memória: da liberdade à tirania. Revista MUSAS, n. 4, 2009, pp. 6-10. . Entre memória e história: a problemática dos lugares. Projeto História, v. 10, 1993, pp. 7-28.

OLICK, Jeffrey K. Collective memory: The two cultures. Sociological Theory, v. 17, n. 3, 1999, pp. 333-348.

. In the House of the Hangman: The Agonies of German Defeat, 1943-1949. Chicago, University of Chicago Press, 2005.

OLICK, Jeffrey. K.; ROBBINS, Joyce. Social memory studies: From "collective memory" to the historical sociology of mnemonic practices. Annual Review of Sociology, 1998, pp. 105-140.

OLICK, Jeffrey K.; VINITZKI-SEROUSSI, Vered; LEVY, Daniel. The Collective Memory Reader. New York, Oxford University Press, 2011.

OLSEN, Tricia D.; PAYNE Leigh A.; RITTER, Andrew G. Superando a Impunidade na América Latina. In: SILVA FILHO, José Carlos Moreira da.; ABRÃO, Paulo; TORELLY, Marcelo D. Justiça de Transição nas Américas: olhares interdisciplinares, fundamentos e padrões de efetivação. Belo Horizonte, Editora Fórum, 2013

PAYNE, Leigh. Unsettling Accounts: The Politics and Performance of Confessions by Perpetrators of Authoritarian State Violence. Durham, Duke University Press, 2008.

PERALTA, Elsa. Abordagens teóricas ao estudo da memória social: uma resenha crítica. Arquivos da Memória: Antropologia, escala e memória. n. 2, 2007, pp. 4-23.

POLLAK, Michael. Memória, esquecimento, silêncio. Revista Estudos Históricos, v. 2, n. 3, 1989, pp. 3-15.

PORTELLI, Alessandro. O massacre de Civitella Val di Chiana: mito, política, luto e senso comum. In: MORAES FERREIRA, Marieta; AMADO, Janaína (Org.). Usos e abusos da História Oral. Rio de Janeiro, Editora da FGV, 1996, pp. 103-130.

SARLO, Beatriz. Tempo passado: cultura da memória e guinada subjetiva. São Paulo, Companhia das letras, 2007.

TEITEL, Ruti G. Transitional Justice. United States, Oxford University Press, 2000.

VINYES, Ricard. Sobre Vítimas e vazios, ideologias e reconciliações, privatizações e impunidades. In: QUADRAT, Samantha Viz; ROLLEMBERG, Denise. História e Memória das Ditaduras do Século XX, Rio de Janeiro, v. 2, Editora da FGV, 2015.

WOOD, Nancy. Vectors of Memory: Legacies of Trauma in postwar Europe. Oxford, Berg, 1999.

YOUNG, James Edward. The texture of memory: Holocaust memorials and meaning. Yale, Yale University Press, 1993.

ZAMORA, José Antonio. História, memória e justiça: da Justiça Transicional à justiça anamnética. In: SILVA FILHO, José Carlos Moreira; ABRÃO, Paulo; TORELLY, 
Marcelo D. (Coord.) Justiça de Transição nas Américas: olhares interdisciplinares, fundamentos e padrões de efetivação. Belo Horizonte, Editora Fórum, 2013, pp. 21-46.

Recebido em: 04/09/2018

Aprovado em: 20/03/2020

\section{Como citar este artigo:}

GOULART, Barbara. Reflexões Sociológicas Sobre Memória e Política. Contemporânea Revista de Sociologia da UFSCar, v. 10, n. 1, jan.- abril 2020, pp. 203-228. 